\title{
The analysis of fungal alkaloids in plant fluids
}

\author{
A. KOULMAN ${ }^{1}$, M.J. VAN GILS ${ }^{1,2}$, G. A. LANE ${ }^{1}$, M.J. CHRISTENSEN ${ }^{1}$, K. FRASER ${ }^{1}$ and B.A. TAPPER \\ ${ }^{1}$ AgResearch Limited, Tennent Drive, Private Bag 11008, Palmerston North, New Zealand \\ ${ }^{2}$ Groninging Research Institute for Pharmacy, University of Groningen, A. Deusinglaan 1, Groningen, The Netherlands \\ albert.koulman@agresearch.co.nz
}

\begin{abstract}
Many grasses live in association with fungi (Neotyphodium spp. endophytes) growing in the intercellular spaces of the grass. The endophytes produce a range of alkaloids that protect the grass against grazing animals and insects. There has been speculation about the mobilisation and translocation of different alkaloids. We aimed to determine if metabolites produced by endophytes are mobilised and translocated by the plant. We developed a versatile method for the analysis plant fluids, using a linear ion trap mass spectrometer. Cut leaf fluid and guttation fluid of different grass endophyte associations in ryegrass and tall fescue were analysed. Peramine was detected in the cut leaf and guttation fluid of all ryegrass-endophyte associations that are able to produce peramine, but were found only in the cut leaf fluid of the tall fescue association. Lolines and ergot peptides were also detected in some associations.
\end{abstract}

Keywords: Neotyphodium, ryegrass, tall fescue, guttation, peramine, ergovaline, loline

\section{Introduction}

Different species of grasses grow in association with a fungal endophyte such as perennial ryegrass (Lolium perenne L.) with Neotyphodium lolii (Latch, Christensen, \& Samuels) Glenn, Bacon \& Hanlin. The endophyte grows in the intercellular spaces of the grass plant and produces a range of alkaloids, such as ergot alkaloids and indole diterpenes, which can cause animal toxicoses (Fletcher 2005; Siegel et al. 1985). Other alkaloids produced by the endophyte, like the unusual pyrrolopyrazine alkaloid peramine, deter herbivorous insects (Rowan \& Gaynor 1986).

A recent study showed that each of the classes of alkaloids has its own characteristic intra-plant distribution in ryegrass, although the distribution is variable between different host genotypes (Spiering et al. 2005). The main indolediterpenoid, lolitrem B, accumulates over time in older tissue and is present at only low levels in young tissue. Ergovaline is concentrated in the stem and basal leaf sheath of intermediate age. Peramine, however, is fairly evenly distributed in plant tissues and does not accumulate in older tissues (Ball et al. 1997; Spiering et al. 2002; Spiering et al. 2005). One of the explanations for these differences in distribution could be that lolitrem $\mathrm{B}$ remains within the endophyte hyphae, and ergovaline is associated with fungal growth in particular tissues, while peramine is translocated from the endophyte into plant intercellular spaces where it is either metabolised or mobilised.

One way in which plants are able to dispose of unwanted compounds is via the mechanism of guttation, a process occuring water under conditions of high humidity in which eccess water is exuded. The guttation droplets are formed by special tissues called hydathodes, which are located at the tip of the leaf (Taiz \& Zeiger 1991). It has been shown that xenobiotics, like griseofulvin and other antibiotics, which can be taken up by the roots of a plant and are not metabolised within the plant, can be excreted into the guttation fluid (Bollard 1960). Because peramine is not produced by the plant itself, our hypothesis was that peramine released by the endophyte into the apoplastic spaces could appear in guttation fluid. We expected the levels of peramine to be low and therefore difficult to measure with existing HPLC-UV analysis (Spiering et al. 2005). We were able to show the presence of peramine in plant fluids (Koulman et al. in press). In this study we show the results of different associations on a range of endophyte alkaloids in guttation fluid, and fluids from cut leaves.

\section{Materials and Methods}

\section{Plant material}

Tall fescue and ryegrass plants with or without endophyte (Table 1) were grown in a potting mix treated with a systemic insecticide, imidacloprid (Bayer, NZ), in individual pots in the greenhouse. The original seed lines were obtained from the Margot Forde Forage Germplasm Centre, AgResearch Grasslands, Palmerston North, New Zealand. The associations used in this study were naturally infected or artificially infected populations of perennial ryegrass (Lolium perenne) cv. Nui 5 or Samsom with Neotyphodium lolii strains (CTE, AR1 or AR37), or tall fescue (Festuca arundinacea) with Neotyphodium coenophialum. The endophyte-free plants used in this study are descendants of plants that were obtained by treating infected tillers with benomyl fungicide. All the plants were regularly checked for the presence or absence of the expected endophyte.

To collect fluid, plants were placed overnight in a closed container. Beforehand some leaves were cut with scissors, approximately $5 \mathrm{~cm}$ from the leaf tip. In early morning the fluid accumulated at the leaf tips or cut ends of individual plants were collected with a pipette, transferred to plastic containers, and stored at $-20^{\circ} \mathrm{C}$ until analysis.

\section{Analysis of fluids}

LC/MS-MS was performed on a C18 Luna column (Phenomenex Torrence, CA, USA) $(150 \times 2 \mathrm{~mm}, 5 \mu \mathrm{m})$ at a flow rate of $200 \mu \mathrm{l}$ min $^{-1}$ using a Thermo Finnigan Surveyor HPLC system with a solvent gradient (solvent $\mathrm{A}$ : $\mathrm{H}_{2} \mathrm{O} 0.1 \%$ formic acid; $\mathrm{B}$ : $\mathrm{MeCN}$ $0.1 \%$ formic acid), starting with $3 \% \mathrm{~B}, 97 \%$ A for 5 minutes and then increasing to $23 \% \mathrm{~B}$ over 15 minutes followed by a column wash at $95 \%$ B

Mass spectra were determined with a linear ion trap mass spectrometer (Thermo LTQ) using ESI in +ve mode. Nformylloline $(183 \mathrm{~m} / \mathrm{z})$ was detected in SRM using the main fragment $155 \mathrm{~m} / \mathrm{z}$. Peramine was detected in SRM mode, selecting $248.2 \mathrm{~m} / \mathrm{z}$ and quantifying the 175.1 and $206.2 \mathrm{~m} / \mathrm{z}$ fragment ions. Ergovaline was detected in SRM mode, selecting $534.4 \mathrm{~m} / z \pm 2,35 \%$ relative collision energy, and quantifying the sum of intensities of the 208,223,268, $320 \mathrm{~m} / \mathrm{z}$ fragment ions. Relative concentrations are reported.

\section{Results and Discussion}

Droplets were collected from intact leaf tips and cut leaves from several grass endophyte associations as mentioned in Table 1. Peramine was detected in the cut leaf fluid from all studied associations except AR37 which does not accumulate peramine (see Table 1). The levels of peramine in both cut leaf fluid and in 
Table 1 Species of perennial ryegrass (Lolium perenne) and tall fescue (Festuca arundiacea) with their endophyte association and alkaloid level.

\begin{tabular}{llcccccc}
\hline \multirow{2}{*}{ Plant } & \multirow{2}{*}{ Endophyte } & \multicolumn{2}{c}{ Peramine } & \multicolumn{2}{c}{ Ergovaline } & \multicolumn{2}{c}{ N-formylloline } \\
\cline { 2 - 7 } & & Cut Leaf & Guttation & Cut Leaf & Guttation & Cut Leaf & Guttation \\
\hline Ryegrass & None & $\mathrm{ND}^{\mathrm{a}}$ & $\mathrm{ND}$ & $\mathrm{ND}^{\mathrm{a}}$ & $\mathrm{ND}^{\mathrm{a}}$ & $\mathrm{ND}^{\mathrm{a}}$ & $\mathrm{ND}^{\mathrm{a}}$ \\
Ryegrass & E.festucae Fl1) & +++ & ++ & ++ & + & $\mathrm{ND}^{\mathrm{a}}$ & $\mathrm{ND}^{\mathrm{a}}$ \\
Ryegrass & N. loilii WT & +++ & +++ & + & $+/-$ & $\mathrm{ND}^{\mathrm{a}}$ & $\mathrm{ND}^{\mathrm{a}}$ \\
Ryegrass & N. lolii AR1 & +++ & + & $\mathrm{ND}^{\mathrm{a}}$ & $\mathrm{ND}^{\mathrm{a}}$ & $\mathrm{ND}^{\mathrm{a}}$ & $\mathrm{ND}^{\mathrm{a}}$ \\
Ryegrass & N. lolii AR37 & $\mathrm{ND}^{\mathrm{a}}$ & $\mathrm{ND}$ & $\mathrm{ND}$ & $\mathrm{ND}^{\mathrm{a}}$ & $\mathrm{ND}^{\mathrm{a}}$ & $\mathrm{ND}^{\mathrm{a}}$ \\
Tall fescue & N. coenophialum WT & +++ & $\mathrm{ND}^{\mathrm{a}}$ & ++ & + & ++++ & +++ \\
\hline
\end{tabular}

$\mathrm{ND}=$ not detected (The limit of detection $0.8 \mathrm{ng} \mathrm{ml}^{-1}$ ), $+/-=<5 \mathrm{ng} \mathrm{ml}^{-1},+=5-50 \mathrm{ng} \mathrm{ml}^{-1},++=50-500$ $\mathrm{ng} \mathrm{ml}^{-1},+++=500-5000 \mathrm{ng} \mathrm{ml}^{-1},++++<5000 \mathrm{ng} \mathrm{ml}^{-1}$

guttation fluid differ quite widely from plant to plant (Koulman et al. in press). The levels of alkaloids produced by different grassendophyte associations have previously been observed to differ appreciably (Keogh et al. 1996; Ball et al. 1997; Spiering et al. 2002) and even between clonal plants with the same endophyte (Spiering et al. 2005). In addition differences in root pressure may cause even more fluctuations in the final concentration of peramine in the fluids. The presence of peramine in guttation fluids shows unambiguously that peramine is mobilised from within the fungus, taken up into the xylem and exuded via the hydathodes. While mobilisation of endophyte alkaloids within the plant has been previously postulated (Spiering et al. 2005), this study (Koulman et al. in press) has provided the first direct evidence that alkaloids produced by the endophyte are mobilised and translocated by the host plant.

Peramine was found in the guttation fluid of four out of the five associations that accumulated peramine (see Table 1). The concentration of imidacloprid, a systemic insecticide (which was routinely used to control glasshouse pests) was up to tenfold higher in guttation fluid than in cut-leaf fluid, suggesting the active exudation of these compounds. As shown in Table 1 there was not such a marked difference observed for peramine. No peramine was found in guttation fluid from infected tall fescue, suggesting that this plant association retains peramine inside the plant, while for perennial ryegrass the concentration of peramine in exuded fluid was at a similar level to that inside the leaf. These results could be explained by a regulated process controlling the concentration of peramine leaving the plant. The concentration of peramine found in guttation fluid does not yield enough peramine to suggest a feeding deterrent effect on insects. The minimal concentration of peramine that shows any effect is at least $0.1 \mu \mathrm{g} / \mathrm{g}$ plant material (Rowan et al. 1990). This would mean that wild type perennial ryegrass would need $0.2 \mathrm{~mL}$ of guttation to protect $1 \mathrm{~g}$ of plant material. Generally we were not able to collect more than $0.1 \mathrm{~mL}$ (often less) of guttation fluid from one tiller.

The tall fescue $N$. coenophialum association produces loline alkaloids in high concentration as well as ergot peptide alkaloids, and the guttation fluids contained detectable levels of both these alkaloid classes. We could clearly detect $\mathrm{N}$-acetylloline and $\mathrm{N}$ formylloline. The concentration of lolines in guttation fluid ranged from 1 to $10 \mu \mathrm{g} / \mathrm{ml}$. Because of the lack of sufficient literature on the concentration dependency of the anti-insect activity of lolines (Wilkinson et al. 2000), it is impossible to estimate if the levels of lolines in guttation fluid would cause any serious effects on insects. However, because the levels in guttation fluid are much lower than in the tissue, it seems unlikely that there is any direct insecticidal effect of the fluid.

The ergot peptide alkaloid, ergovaline, was identified in the tall fescue $N$. coenophialum association on the basis of its mass spectrometric fragmentation pattern (Lehner et al. 2005) and coelution with a standard and its concentration was calculated as ergotamine equivalents. Ergovalinine and dehydroergovaline were tentatively identified in the cut leaf fluid on the basis of the $\mathrm{m} / \mathrm{z}$ and retention time, but we did not obtain fragmentation data to confirm their identity. The levels of ergovaline and lolines in guttation fluid were about 0.01 and 0.02 that of the levels in cut leaf fluid, respectively. We could only detect ergovaline in the fluids from perennial ryegrass infected with Neotyphodium lolii or Epichloë festucae which also accumulate ergopeptide alkaloids.

The ecological significance of this process of exudation remains to be elucidated. As mentioned before the levels are much lower than in tissue. Still insect deterrent compounds on the outside of the plant could have some effect and prevent foraging of insects that, for instance, already have encountered high levels of insecticides through the consumption of endophyte infected grasses. To what extent the plant redistributes fungal alkaloids and what the ecological role of such mobilisation is, remains difficult to predict. However, the high sensitivity now offered by LC-MS/MS SRM analytical methods provides new opportunities for examining these processes in detail, with higher resolution in space and time to resolve these questions.

\section{ACKNOWLEDGEMENTS}

We acknowledge the support of the Foundation for Research Science and Technology, Contract C10X0203 New opportunities from Forage Plant Genomics and the AgResearch Board for Reinvestment funding for metabolomics.

\section{REFERENCES}

Ball, O.J.P.; Barker, G.M.; Prestidge, R.A.; Lauren, D.R. 1997. Distribution and accumulation of the alkaloid peramine in Neotyphodium lolii-infected perennial ryegrass. Journal of Chemical Ecology 23: 1419-1434.

Bollard, E.G. 1960. Transport in the xylem. Annual Review of Plant Physiology 11: 141-166.

Fletcher, L.R. 2005. Managing ryegrass-endophyte toxicoses. pp. 229-241. In: Neotyphodium in Cool-Season Grasses. Eds. 
Roberts, C. A.; West, C. P.; Spiers, D. E. Blackwell Publishing, Ames, USA.

Keogh, R.G.; Tapper, B.A.; Fletcher, R.H. 1996. Distributions of the fungal endophyte Acremonium lolii, and of the alkaloids lolitrem B and peramine, within perennial ryegrass. New Zealand Journal of Agricultural Research 39: 121-127.

Koulman, A.; Lane, G.A.; Christensen, M.J.; Fraser, K.; Tapper, B.A. 2007. Peramine and other fungal alkaloids are exuded in the guttation fluid of endophyte-infected grasses. Phytochemistry 68:355-360

Lehner, A.F.; Craig, M.; Fannin, N.; Bush, L.; Tobin, T. 2005. Electrospray $[+]$ tandem quadrupole mass spectrometry in the elucidation of ergot alkaloids chromatographed by HPLC: Screening of grass or forage samples for novel toxic compounds. Journal of Mass Spectrometry 40: 1484-1502.

Rowan, D.D.; Gaynor, D.L. 1986. Isolation of feeding deterrent s against stem weevil from ryegrass infected with the endophyte Acremonium loliae. Journal of Chemical Ecology 12: 647-658.
Siegel, M.R.; Latch, G.C.M.; Johnson, M.C. 1985. Acremonium fungal endophytes of tall fescue and perennial ryegrass significance and control. Plant Disease 69: 179-183.

Spiering, M.J.; Davies, E.; Tapper, B.A.; Schmid, J.; Lane, G.A. 2002. Simplified extraction of ergovaline and peramine for analysis of tissue distribution in endophyte-infected grass tillers. Journal of Agricultural and Food Chemistry 50: 5856-5862.

Spiering, M.J.; Lane, G.A.; Christensen, M.J.; Schmid, J. 2005. Distribution of the fungal endophyte Neotyphodium lolii is not a major determinant of the distribution of fungal alkaloids in Lolium perenne plants. Phytochemistry 66: 195-202.

Taiz, L.; Zeiger, E. 1991. Plant Physiology. The Benjamin/ Cummings Publishing Company Inc, Redwood City, Ca. pp.

Wilkinson, H.H.; Siegel, M.R.; Blankenship, J.D.; Mallory, A.C.; Bush, L.P.; Schardl, C.L. 2000. Contribution of fungal loline alkaloids to protection from aphids in a grass-endophyte mutualism. Molecular Plant-Microbe Interactions 13: 1027-1033. 